(2) Open Access Full Text Article

\title{
Comprehensive evaluation of formulation factors for ocular penetration of fluoroquinolones in rabbits using cassette dosing technique
}

This article was published in the following Dove Press journal:

Drug Design, Development and Therapy

22 February 2016

Number of times this article has been viewed

\author{
Charu Sharma ${ }^{1,2}$ \\ Nihar R Biswas' \\ Shreesh Ojha ${ }^{3}$ \\ Thirumurthy Velpandian' \\ 'Department of Ocular \\ Pharmacology and Pharmacy, All \\ India Institute of Medical Sciences, \\ New Delhi, India; '2Department of \\ Internal Medicine, ${ }^{3}$ Department of \\ Pharmacology and Therapeutics, \\ College of Medicine and Health \\ Sciences, United Arab Emirates \\ University, AI Ain, UAE
}

Objective: Corneal permeability of drugs is an important factor used to assess the efficacy of topical preparations. Transcorneal penetration of drugs from aqueous formulation is governed by various physiological, physiochemical, and formulation factors. In the present study, we investigated the effect of formulation factors like concentration, $\mathrm{pH}$, and volume of instillation across the cornea using cassette dosing technique for ophthalmic fluoroquinolones (FQs).

Materials and methods: Sterile cocktail formulations were prepared using four congeneric ophthalmic FQs (ofloxacin, sparfloxacin, pefloxacin mesylate, and gatifloxacin) at concentrations of $0.025 \%, 0.5 \%$, and $0.1 \%$. Each formulation was adjusted to different $\mathrm{pH}$ ranges $(4.5,7.0$, and 8.0 ) and assessed for transcorneal penetration in vivo in rabbit's cornea ( $n=4$ eyes) at three different volumes $(12.5,25$, and $50 \mu \mathrm{L})$. Aqueous humor was aspirated through paracentesis after applying local anesthesia at $0,5,15,30,60,120$, and 240 minutes postdosing. The biosamples collected from a total of 27 groups were analyzed using liquid chromatography-tandem mass spectroscopy to determine transcorneal permeability of all four FQs individually.

Results: Increase in concentration showed an increase in penetration up to $0.05 \%$; thereafter, the effect of concentration was found to be dependent on volume of instillation as we observed a decrease in transcorneal penetration. The highest transcorneal penetration of all FQs was observed at $\mathrm{pH} 7.0$ at concentration $0.05 \%$ followed by $0.025 \%$ at $\mathrm{pH} 4.5$. Lastly, increasing the volume of instillation from 12.5 to $50 \mu \mathrm{L}$ showed a significant fall in transcorneal penetration.

Conclusion: The study concludes that formulation factors showed discernible effect on transcorneal permeation; therefore, due emphasis should be given on drug development and design of ophthalmic formulation.

Keywords: transcorneal penetration, ophthalmic, in vivo, antibacterial

\section{Introduction}

Ophthalmic drugs have mainly originated from oral dosage forms without much scientific exploration and rationale, which has led to their low ocular bioavailability. Even the drugs administered systemically have poor access to eye because of the blood-aqueous and blood-retinal barriers. ${ }^{1}$ Topical instillation is a common mode to combat ocular infections even though a large amount of drugs are eliminated from precorneal surface leading to low bioavailability $(<5 \%)$. Additionally, cornea acts as an effective barrier for drug penetration due to the annular tight junctions (zonula occludens) in corneal epithelium. ${ }^{2}$

Although ophthalmic drugs were not given much importance in the past, recently, various formulational approaches have been attempted to circumvent their shortcomings and improve the ocular pharmacokinetics. ${ }^{3}$ There are numerous factors
Correspondence: Thirumurthy Velpandian Department of Ocular Pharmacology and Pharmacy, All India Institute of Medical Sciences, Ansari Nagar, New Delhi I 10029, India

Tel +9 I II 26593162

Fax +9| II 26588919

Email tvelpandian@gmail.com
Drug Design, Development and Therapy 2016:10 81 I-823

(c) (1) (8) ๑ 2016 Sharma et al. This work is pulished and licensed by Dove Medical Press Limited. The full terms of this license are available at https:/www.dovepress.com/terms.php cc. hereby accept the Terms. Non-commercial uses of the work are permitted without any further permission from Dove Medical Press Limited, provided the work is properly attributed. For permision for commercial use of this work, please see paragraphs 4.2 and 5 of our Terms (https://www. doverperess.com/terms.php).
Dovepress

http://dx.doi.org/10.2147/DDDT.S95870 \section{I}


which affect transcorneal penetration of drug across cornea mainly the formulation factors (concentration, $\mathrm{pH}$, volume of instillation, irrigant preservatives, osmolarity, viscosity, bioadhesive nature, etc), physiological factors (small absorptive surface and low transparency of cornea, lipophilicity of corneal epithelium, etc), and physiochemical factors (degree of ionization of drug in tear film, nonspecific irritation by drug leading to reflux tear flow, metabolism, enzymolysis, bonding of the drug with proteins contained in tear fluid, defense mechanisms, etc). ${ }^{4,5}$

Topical fluoroquinolones (FQs) are commonly used in ocular bacterial infections due to their unprecedented mode of action, broad-spectrum bactericidal activity equally comparative to other semi-synthetic antibiotics, low toxicity, etc. Currently, various FQs (ciprofloxacin, sparfloxacin, ofloxacin, pefloxacin mesylate, moxifloxacin, and gatifloxacin) represent the leading ophthalmic products. ${ }^{1,6,7}$

Cassette dosing is a high-throughput screening technique to increase throughput and reduce animal use. ${ }^{8,9}$ The technique requires selective bioanalytical methods to quantitate each of the administered compounds in each collected sample. The use of sophisticated analytical tools like liquid chromatography-tandem mass spectroscopy (LC-MS/MS) has enabled the quantification of drugs in minuscule samples. ${ }^{10-12}$

Limited studies have been reported with the use of cassette dosing technique to determine in vitro permeability coefficient of drugs. ${ }^{13-15}$ Some studies have reported the de novo methods to determine corneal permeability in experimental animals. ${ }^{16,17}$ Limited studies have been reported on use of this to determine in vivo transcorneal permeability of drugs. Moreover, the reported in vitro ocular studies still remain uncorroborated due to the absence of several precorneal dynamic factors, which emerge during the actual in vivo process. Recently, a finding from our laboratory showed the correlation between the pharmacokinetic profiles derived from in vivo cassette dosing data with corneal permeability for the successful quantitative structure-property relationship approach. ${ }^{18}$ Further, a detailed systematic study on effect of various formulation factors on corneal permeability was considered important for ocular-specific drug development. Therefore, the present study was conceived to study the effect of formulation factors like concentration of drug, $\mathrm{pH}$ of the formulation, and volume of drug instillation on transcorneal permeation of FQs using cassette dosing in rabbits. The congeneric topically used FQs, viz ofloxacin, sparfloxacin, pefloxacin mesylate, and gatifloxacin, were selected, and their transcorneal penetration across the cornea was determined using LC-MS/MS.

\section{Materials and methods Chemicals and equipment}

Pure standard powder of ofloxacin, pefloxacin mesylate, sparfloxacin (Cipla Ltd., Mumbai, India), and gatifloxacin (Sun Pharma, Mumbai, India) was obtained as gratis samples. Other chemicals like acetonitrile of mass spectroscopy (MS) grade (E. Merck, Darmstadt, Germany), methanol of high-performance liquid chromatography (HPLC) grade (SD Fine Chemicals Ltd., Mumbai, India), formic acid of MS grade (E.22q Merck, KGaA, Darmstadt, Germany), hydrochloric acid of analytical reagent (AR) grade (SD Fine Chemicals Ltd.), ortho-phosphoric acid of AR grade (Spectrochem Private Ltd, Mumbai, India), boric acid of AR grade (Qualigens, Mumbai, India), sodium hydroxide of AR grade (Central Drug Labs, Kolkata, India), xylocaine (4\%) (Astra IDL, Bangalore, India), and $0.22 \mu \mathrm{m}$ filters (E. Merck) were procured from their standard commercial suppliers. Water was produced in-house by Milli-Q purification system (Millipore, Billerica, MA, USA).

The protocol was approved by the standing animal ethics committee of All India Institute of Medical Sciences, India. The Institutional Animal Ethics Committee clearance number is $418 / 0708$. New Zealand albino rabbits of either sex $(1.5-2 \mathrm{~kg})$ were procured from central animal house facility. The animals were housed in a temperature-controlled room at $24^{\circ} \mathrm{C} \pm 2^{\circ} \mathrm{C}$ and humidity $55 \% \pm 15 \%$ and given food and water ad libitum. All experiments were performed in accordance with the Association for Research in Vision and Ophthalmology Statement for the Use of Animals in Ophthalmic and Vision Research.

\section{Preparation of the cocktail formulation}

The sterile cocktail formulation was prepared from four ophthalmic FQs pure standard powder using cassette dosing (N-in-One) technique. Ofloxacin, sparfloxacin, pefloxacin mesylate, and gatifloxacin were dissolved as cocktail at three different concentrations using sterile boric acid (1.9\%) in pyrogen-free water. All the formulations were passed through $0.22 \mu \mathrm{m}$ Millipore filters and autoclaved at $15 \mathrm{lbs}$ for 20 minutes and stored in a cool, dark place.

\section{Effect of concentration on transcorneal penetration}

The cocktail formulation containing ofloxacin, sparfloxacin, pefloxacin mesylate, and gatifloxacin was prepared at three different concentrations, viz $0.1 \%, 0.05 \%$, and $0.025 \%$, in boric acid $(1.9 \%)$ in pyrogen-free water using the protocol described earlier. 


\section{Effect of $\mathrm{pH}$ range on transcorneal penetration}

Each of the three formulations were adjusted to three different $\mathrm{pH}$ ranges of 4.5, 7.0, and 8.0 using dilute acid or base. The osmolarity of all the prepared topical formulations was found to be between 285 and $300 \mathrm{mOsm}$ as measured using micro-osmometer (Precision Systems Inc, Basking Ridge, NJ, USA).

\section{Effect of volume of instillation on transcorneal penetration}

To study the effect of volume of instillation on transcorneal penetration, each sterile cocktail FQ formulation was instilled at three different volumes, viz 12.5, 25.0, and $50.0 \mu \mathrm{L}$, to the cornea of rabbit eyes ( $n=4$ eyes).

\section{In vivo study in rabbits}

All the formulations prepared were individually studied in rabbits. Each formulation was instilled into the lower fornix of rabbit eyes $(n=4)$ at three different drop volumes. The aqueous humor was aspirated using paracentesis at different time intervals at 5, 15,30,60, 120, and 240 minutes postdose. Aspiration was performed by carefully inserting sterile $31 \mathrm{G}$ hypodermic needle (facing bevel up) through corneal limbus after instillation of xylocaine (4\%) as topical anesthesia.
Topical gentamicin was instilled three times a day for 1 day at the end of experiment to avoid any infection. At each time point, $50 \mu \mathrm{L}$ of aqueous humor was aspirated, and a gap of 1 week was given between two consecutive experiments. All the biosamples obtained were stored at $-80^{\circ} \mathrm{C}$ until quantification by $\mathrm{LC}-\mathrm{MS} / \mathrm{MS}$. The schematic representation of study design is depicted in Figure 1.

\section{Quantification of biosamples using LC-MS/MS}

The instrument used for quantification of biosamples was 4000Q trap MS/MS (MDS SCIEX; Applied Biosystems, Foster City, CA, USA) with electrospray ionization in positive mode. The system was controlled by inbuilt Analyst (ver1.4.2) software. The mass scanning was performed using multiple reaction monitoring mode with singly charged ion in positive polarity.

The analytical separation was achieved using Purospher ${ }^{\circledR}$ STAR RP-18 end-capped cartridge column ( $3 \mu \mathrm{m})$ and $55 \mathrm{~mm} \times 4 \mathrm{~mm}$ cartridge column (Merck, Darmstadt, Germany). The column oven temperature was set at $30^{\circ} \mathrm{C}$, and the tray temperature was maintained at $15^{\circ} \mathrm{C}$. Gradient mobile phase containing acetonitrile with formic acid $(0.1 \%)$ and water with formic acid $(0.1 \%)$ was employed. All the solvents were passed through $0.22 \mu \mathrm{m}$ Millipore filters and were degassed using online inbuilt degasser.

\section{Standard fluoroquinolones}

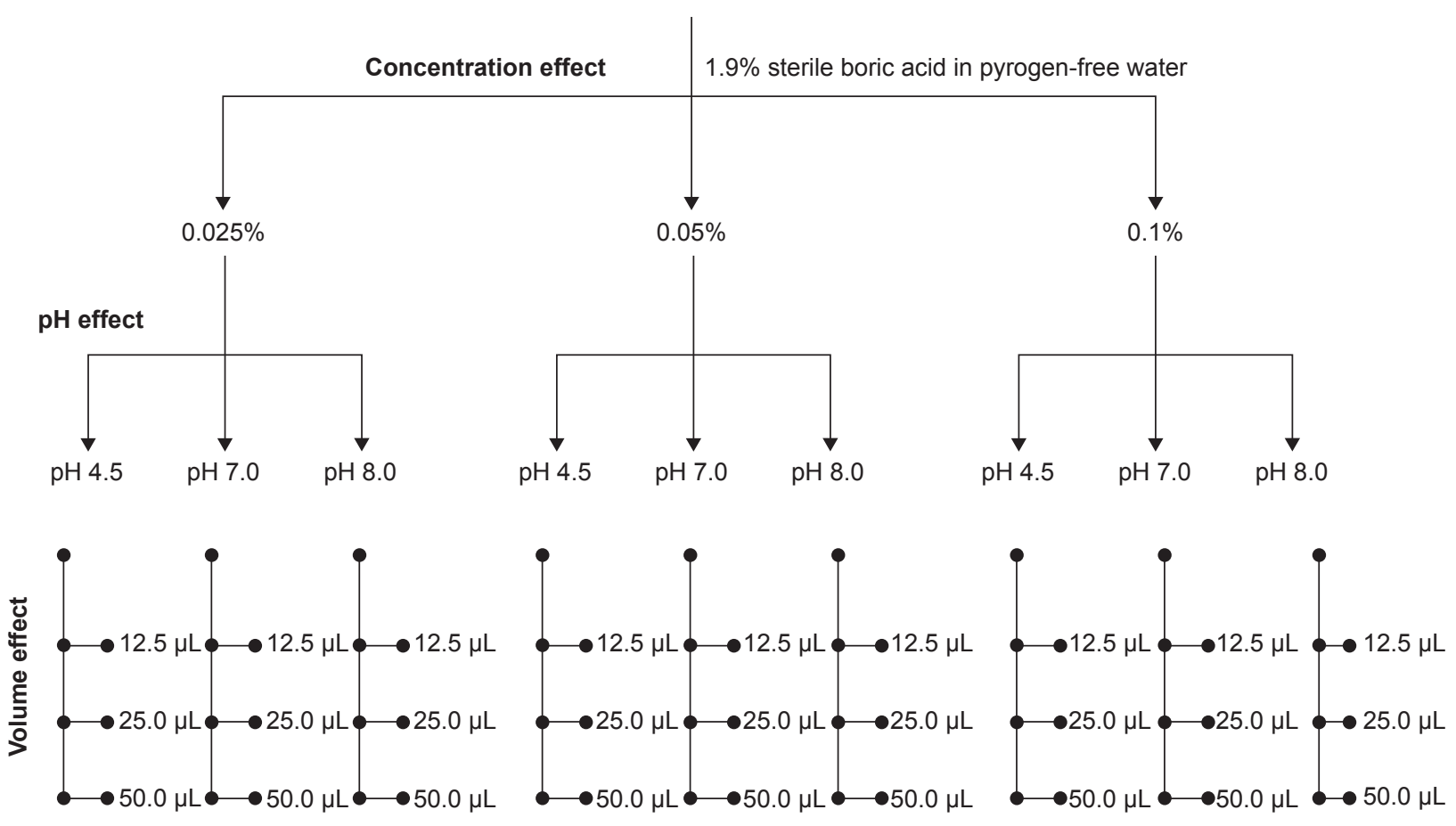

Figure I Schematic representation of the study design. 


\section{Sample preparation}

Analytes for LC-MS/MS were extracted using a deproteinating solvent made of $0.1 \%$ formic acid in pure acetonitrile. Gemifloxacin mesylate was used as the internal standard for all the biosamples. The solvent was mixed with aqueous humor at a ratio of 2:1, vortexed, and then subjected to centrifugation using a microcentrifuge (Remi Scientific, Mumbai, India) at $8,000 \times g$ for 15 minutes. The clear supernatant obtained was subjected for quantification.

\section{Statistical analysis}

Statistical analysis was performed using software like Sigma Plot 11.0 and Sigma Stat 3.5 for all the data sets. All the pharmacokinetic parameters were derived for each $\mathrm{FQ}$. Area under curve (AUC) and percentage penetration were calculated using linear trapezoidal rule and absolute amount of FQ instilled into rabbit cornea. Three-way or two-way analysis of variance was applied to compare the effect of different concentrations, $\mathrm{pH}$ of the formulation, and volumes of drug instillation for all data sets. For pairwise comparison, multiple procedures using Bonferroni $t$-test were employed, and $P<0.05$ was considered as statistically significant.

\section{Results}

Sterile cocktail formulation was instilled in 27 groups with 24 biosamples in each group. All the nine formulations had osmolarity between 285 and $300 \mathrm{mOsm}$. No sign of toxicity or irritation was observed during the study. The biosamples were quantified for the levels of ofloxacin, sparfloxacin, pefloxacin mesylate, and gatifloxacin in aqueous humor. A highly sensitive LC-MS/MS method was developed to elute all the FQs in single run using gradient mobile phase. A gradient method was developed to elute all the studied FQs in single run with different retention times. The mobile phase consisted of water (with $0.1 \%$ formic acid) and acetonitrile (with $0.1 \%$ formic acid) at a gradient flow rate of $0.5-1.0 \mathrm{~mL} / \mathrm{min}$ for 5 minutes.

The spectral masses and different parameters used for the analysis of the FQs are tabulated in Table 1. Figure 2 shows a representative LC-MS spectra for all the FQs. Adequate quality control and blank samples were run in between the groups to avoid analytical errors during estimation. The AUC was calculated for each data set, and the mean AUC was determined for each formulation. The transcorneal penetration was calculated as (mean AUC/absolute amount of drug instilled) $\times 100$ for each formulation.

\section{Effect of concentration on transcorneal penetration}

At $\mathrm{pH} 4.5$, for all the studied FQs, increasing the concentration from $0.025 \%$ to $0.05 \%$ significantly decreased the percentage penetration $(P<0.001)$. Further increasing the FQs concentration to $0.1 \%$ showed a significant decrease in the percentage penetration $(P<0.001)$. At $\mathrm{pH} 7.0$, increasing FQs concentration from $0.025 \%$ to $0.05 \%$ significantly increased transcorneal penetration $(P<0.001)$. However, increasing the concentration to $0.05 \%$ showed a significant effect of volume of drug instillation on the percentage penetration $(P<0.001)$. Further increasing the concentration to $0.1 \%$ showed a fall in percentage penetration as compared to $0.05 \%$. At pH 8.0 , increasing the concentration from $0.025 \%$ to $0.5 \%$ increased the transcorneal penetration significantly $(P<0.05)$. Similar to $\mathrm{pH} 7.0$, further increasing the concentration from $0.05 \%$ to $0.1 \%$ significantly decreased the percentage penetration $(P<0.001)$. Also, concentration $0.05 \%$ showed a significant effect of volume of drug instillation on the percentage penetration $(P<0.001)$. Figures $3-5$ show the AUC graphs for individual FQs at different $\mathrm{pH}$ and volumes of instillation as $12.5,25$, and $50 \mu \mathrm{L}$. Overall effect on transcorneal penetration was found to be increasing at all the FQs concentration from $0.025 \%$ to $0.05 \%$ for the $\mathrm{pH} 7.0-8.0$ as shown by a linear increase followed by a fall in transcorneal penetration $(P<0.001)$. The net effect of concentration on percentage penetration of FQs was dependent on volume of drug instillation up to an extent and was followed by a fall.

\section{Effect of $\mathrm{pH}$ on transcorneal penetration}

At all $\mathrm{pH}$ ranges varying from $\mathrm{pH} 4.5$ to 8.0 , both 12.5 and $25 \mu \mathrm{L}$ drop volumes were taken for cumulative effect analysis.

Table I Spectral masses and different parameters used for the analysis of the fluoroquinolones

\begin{tabular}{llllllll}
\hline FQs & $\begin{array}{l}\text { QI mass } \\
(\mathbf{a m u})\end{array}$ & $\begin{array}{l}\text { Q3 mass } \\
(\mathbf{a m u})\end{array}$ & $\begin{array}{l}\text { Dwell } \\
(\mathbf{m s})\end{array}$ & $\begin{array}{l}\text { Declusturing } \\
\text { potential }\end{array}$ & $\begin{array}{l}\text { Exit } \\
\text { potential }\end{array}$ & $\begin{array}{l}\text { Collision } \\
\text { energy }\end{array}$ & $\begin{array}{l}\text { Collision exit } \\
\text { potential }\end{array}$ \\
\hline Pefloxacin & 334.30 & 205.10 & 500.00 & 85.00 & 10.00 & 41.70 & 5.00 \\
Ofloxacin & 362.20 & 221.20 & 500.00 & 85.00 & 10.00 & 41.70 & 5.00 \\
Gatifloxacin & 376.30 & 261.10 & 300.00 & 85.00 & 10.00 & 41.70 & 5.00 \\
Sparfloxacin & 393.30 & 251.30 & 300.00 & 85.00 & 10.00 & 41.70 & 5.00 \\
Gemifloxacin (IS) & 390.00 & 313.40 & 300.00 & 85.00 & 10.00 & 41.70 & 5.00 \\
\hline
\end{tabular}

Abbreviations: FQs, fluoroquinolones; QI, mass filter quadrupole I; Q3, mass filter quadrupole 3; IS, internal standard. 


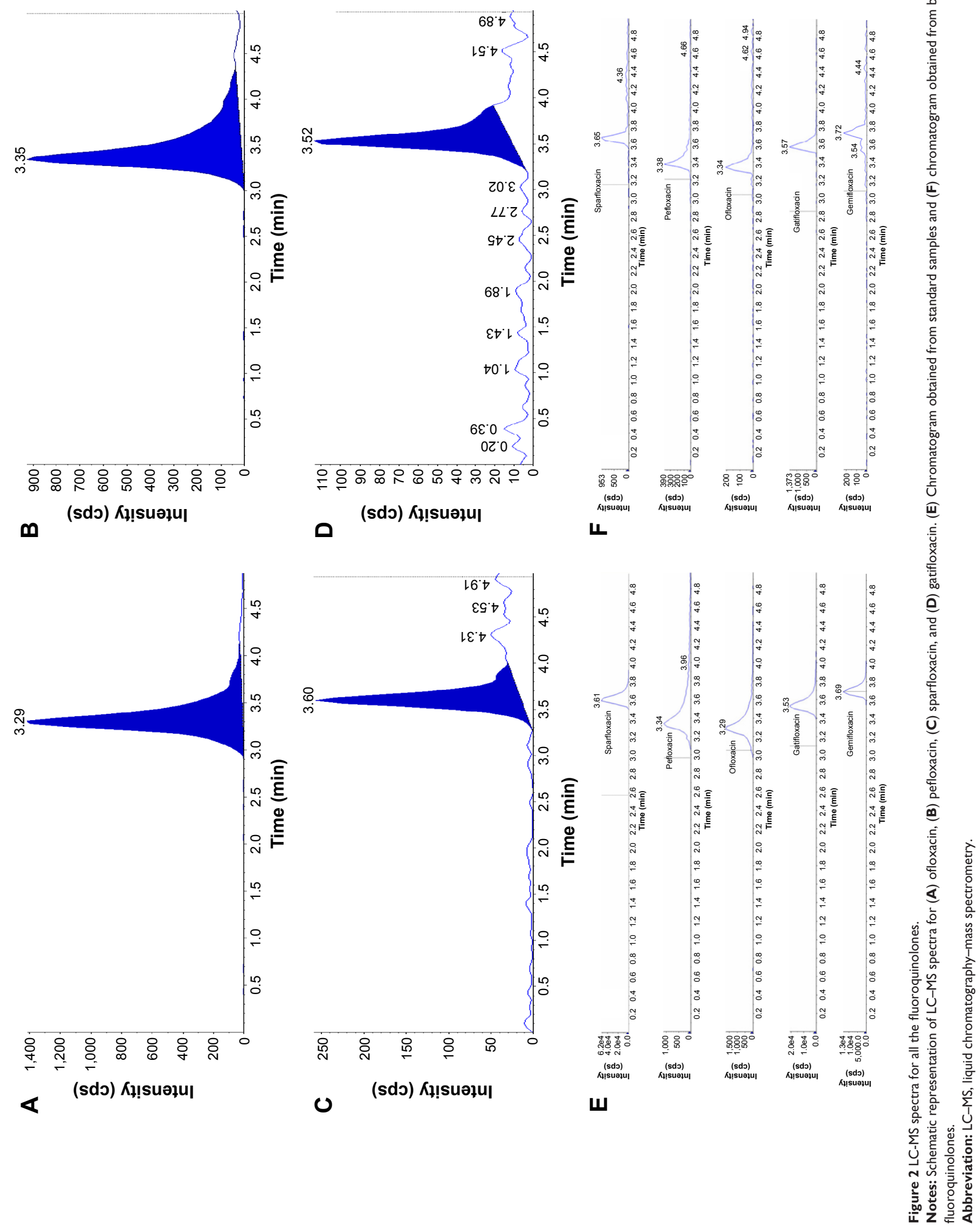




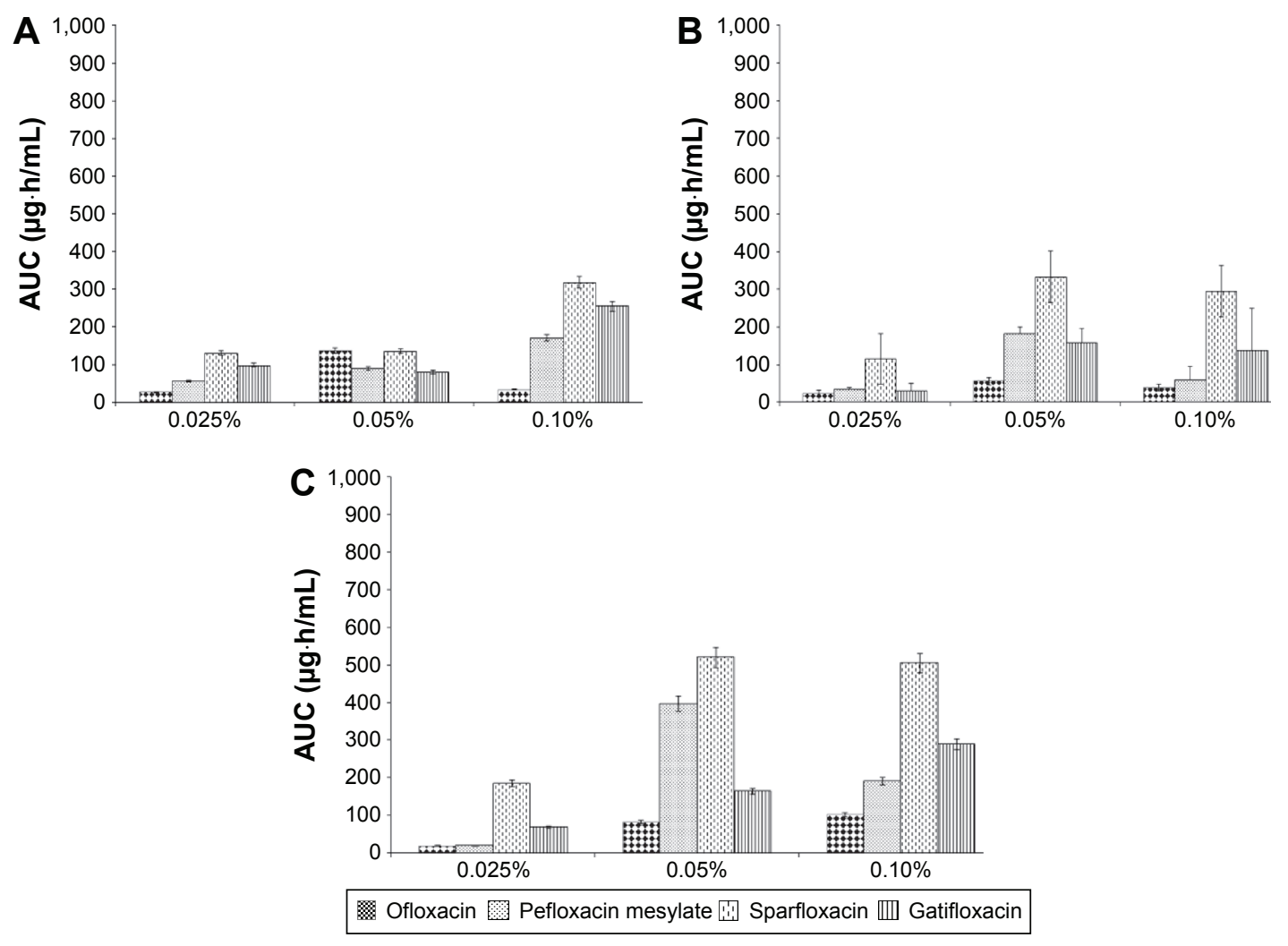

Figure 3 Effect of different concentrations at pH 4.5 (A), pH 7.0 (B), and pH 8.0 (C) on transcorneal penetration of FQs at volume of instillation of $12.5 \mu \mathrm{L}$. Abbreviations: $\mathrm{FQs}$, fluoroquinolones; $\mathrm{AUC}$, area under curve.

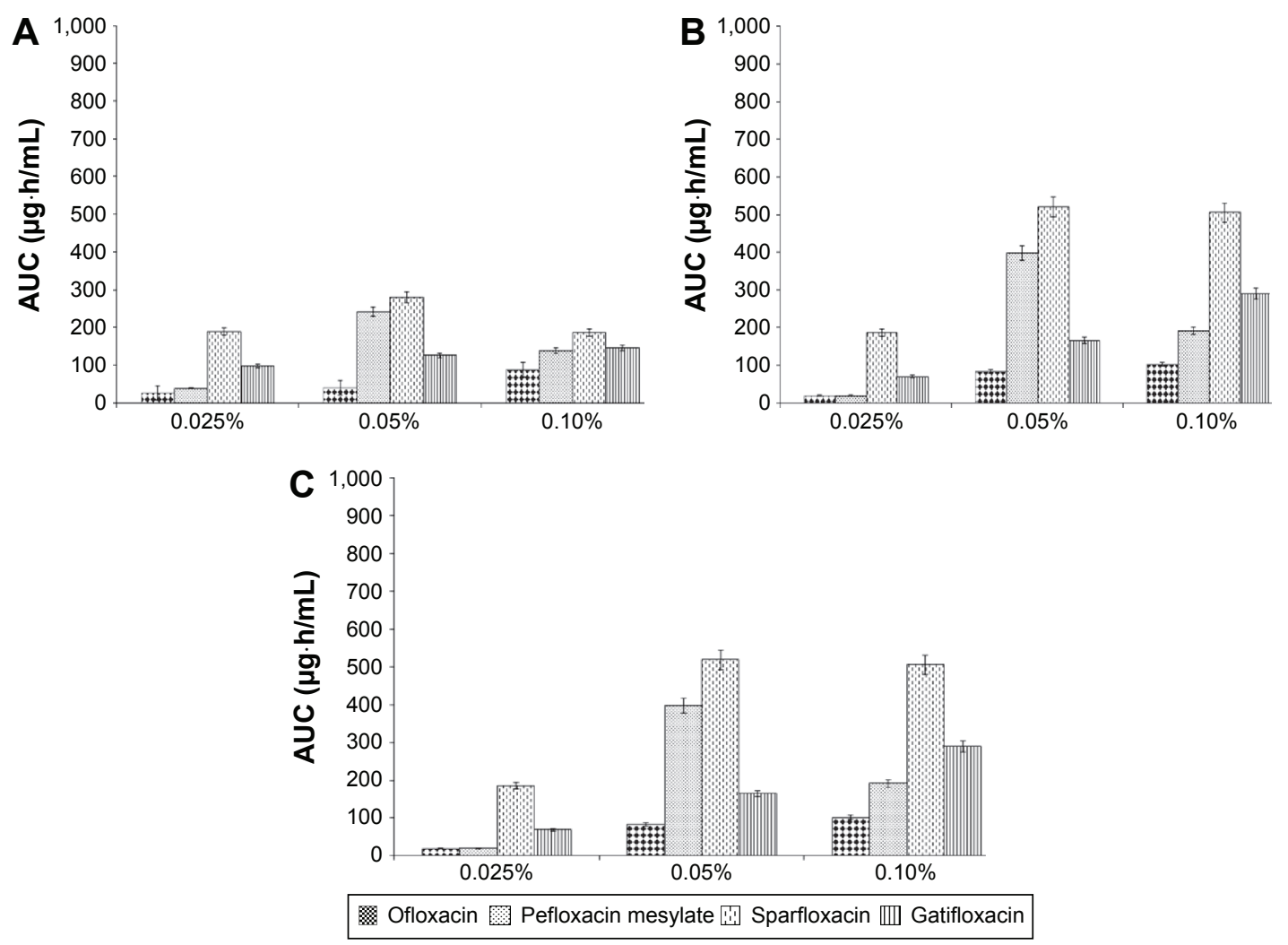

Figure 4 Effect of different concentrations at pH 4.5 (A), pH 7.0 (B), and pH 8.0 (C) on transcorneal penetration of FQs at volume of instillation of $25 \mu \mathrm{L}$. Abbreviations: $\mathrm{FQs}$, fluoroquinolones; $\mathrm{AUC}$, area under curve. 


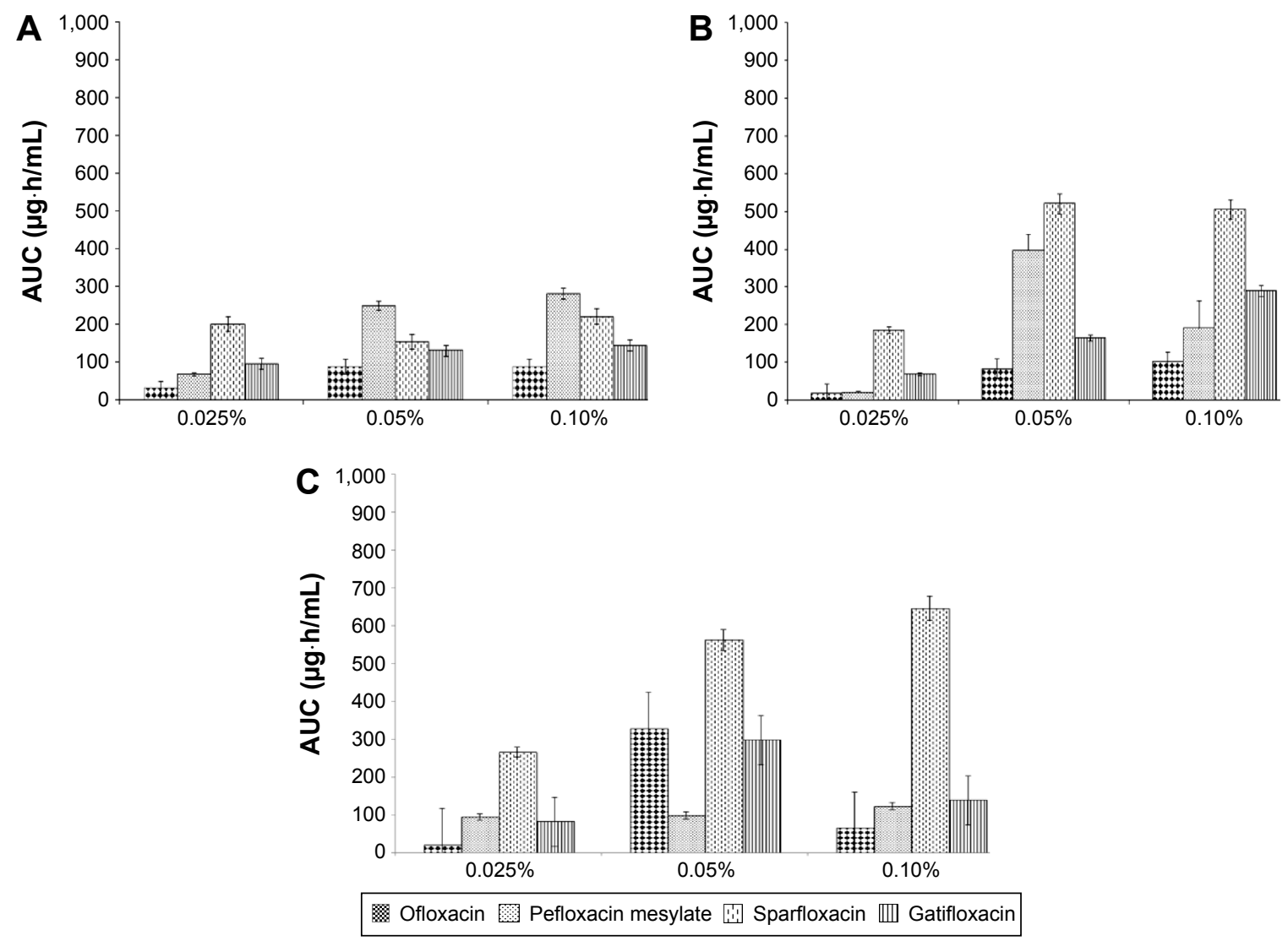

Figure 5 Effect of different concentrations at pH 4.5 (A), pH 7.0 (B), and pH 8.0 (C) on transcorneal penetration of FQs at volume of instillation of $50 \mu \mathrm{L}$. Abbreviations: $\mathrm{FQs}$, fluoroquinolones; $\mathrm{AUC}$, area under curve.

Highest penetration of all the FQs was observed at the $\mathrm{pH} 7.0$ at the concentration of $0.05 \%$ followed by $0.025 \%$ at $\mathrm{pH} 4.5$. Increasing the $\mathrm{pH}$ from 4.5 to 8.0 at both lower and higher FQ concentrations $(0.025 \%$ and $0.1 \%)$ showed a significant fall $(P<0.001)$ in the transcorneal penetration, whereas at $\mathrm{pH} 7.0$, concentration $0.05 \%$ showed a significant increase in transcorneal penetration. This effect was followed by a significant fall when increasing further to $\mathrm{pH}$ 8.0. Figures $6-8$ show the effect of different $\mathrm{pH}$ on transcorneal penetration of FQs at concentration of $0.025 \%, 0.05 \%$, and $0.1 \%$ with drop volume of $12.5,25$, and $50 \mu \mathrm{L}$.

\section{Effect of volume of instillation on transcorneal penetration}

Increasing the volume of drug instillation from 12.5 to $25 \mu \mathrm{L}$ at the $\mathrm{pH} 4.5$ showed a significant decrease in percentage penetration at concentration from $0.025 \%$ to $0.1 \%(P<0.05)$ for all the studied FQs. Further increase in the volume of drug instillation from 25 to $50 \mu \mathrm{L}$ reduced the transcorneal penetration significantly $(P<0.05)$ as compared to $25 \mu \mathrm{L}$. The overall effect of $\mathrm{pH} 4.5$ showed a decrease in transcorneal penetration while increasing the volume of drug instillation $(P<0.001)$.
At the concentration of $0.05 \%$ and $\mathrm{pH} 7.0$, increasing the volume of drug instillation from 12.5 to $25 \mu \mathrm{L}$ showed a slight decrease in transcorneal concentration of FQs $(P<0.05)$. Further increase in volume of drug instillation showed a decrease in the transcorneal penetration. Subgroup analysis at $\mathrm{pH} 7.0$ showed a significant rise in the levels of sparfloxacin $(P<0.05)$. The overall effect shows that increasing volume of instillation at the $\mathrm{pH} 7.0$ decreases transcorneal penetration significantly $(P<0.001)$.

At the concentration of $0.05 \%$ and $\mathrm{pH} 8.0$, increasing the volume of drug instillation from 12.5 to $25 \mu \mathrm{L}$ showed a significant decrease in transcorneal penetration $(P<0.001)$ for FQs. Further increase in volume to $50 \mu \mathrm{L}$ decreases the percentage transcorneal penetration that was found to be statistically insignificant. Net effect of volume of drug instillation on all studied FQs concentration showed significant decrease $(P<0.001)$.

The mean transcorneal penetration showed that irrespective of the $\mathrm{pH}$, increasing the instilled volume of drug instillation from 12.5 to $50 \mu \mathrm{L}$ showed a significant fall in the penetration for the FQs $(P<0.001)$. Figures 9-11 show the AUC graphs for individual FQs at $\mathrm{pH} 4.5, \mathrm{pH} 7.0$, and $\mathrm{pH} 8.0$ and concentration of $0.025 \%, 0.05 \%$, and $0.1 \%$, respectively. 

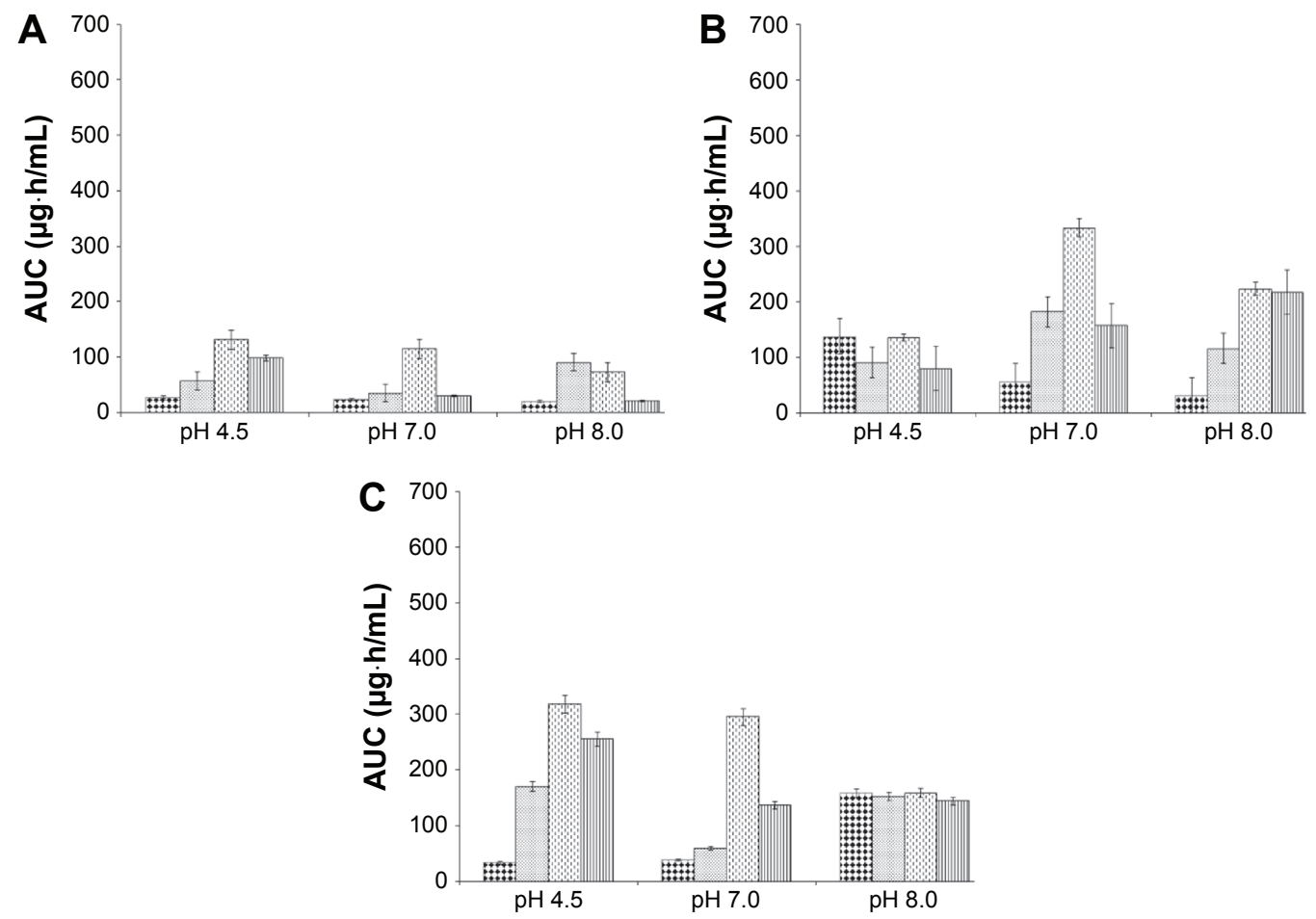

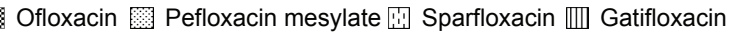

Figure 6 Effect of different $\mathrm{pH}$ on transcorneal penetration of $\mathrm{FQs}$ at concentration of $0.025 \%(\mathbf{A}), 0.05 \%(\mathbf{B})$, and $0.1 \%(\mathbf{C})$ with drop volume of $\mathrm{I} 2.5 \mu \mathrm{L}$. Abbreviations: FQs, fluoroquinolones; AUC, area under curve.

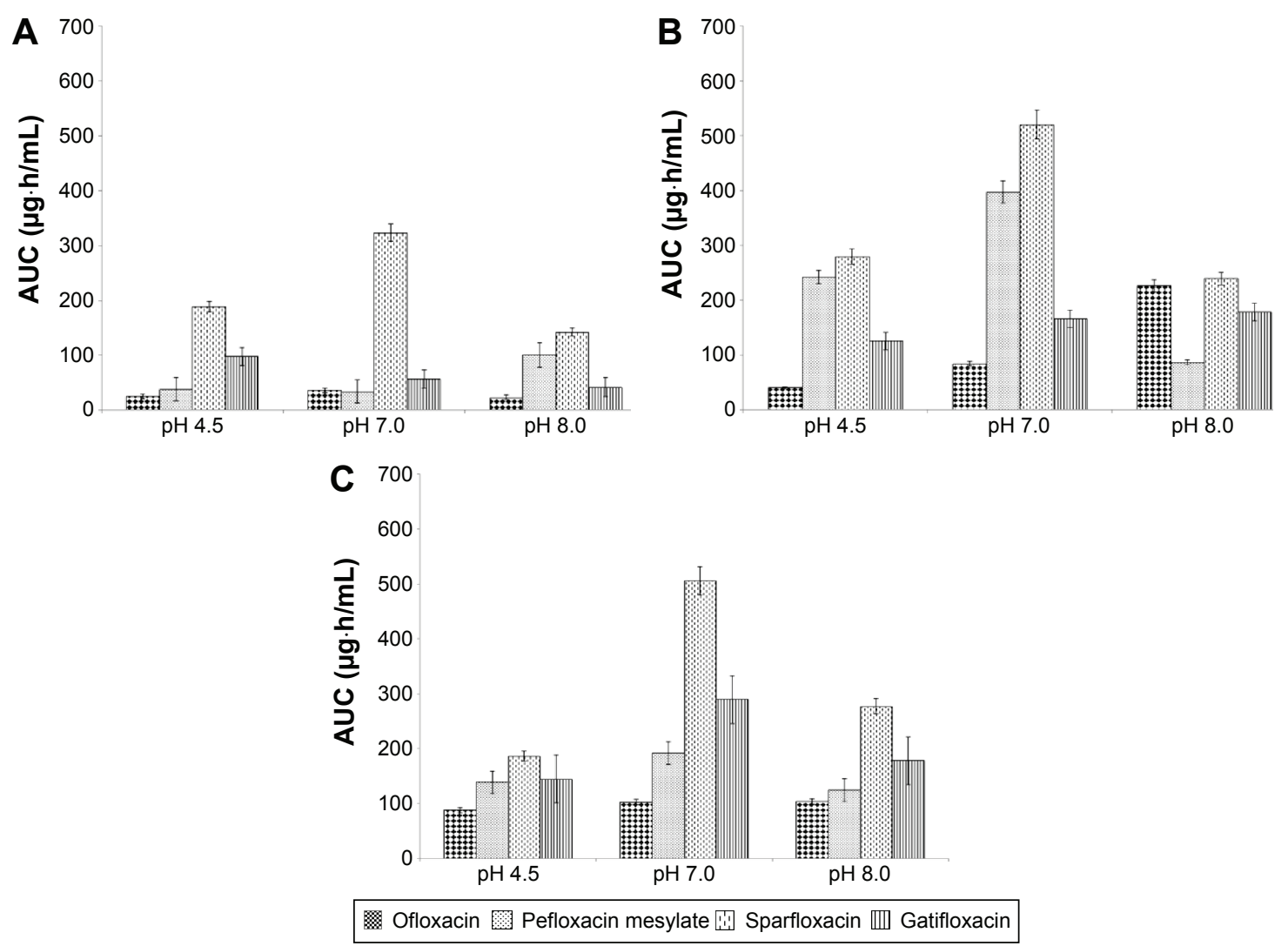

Figure 7 Effect of different $\mathrm{pH}$ on transcorneal penetration of FQs at concentration of $0.025 \%(\mathbf{A}), 0.05 \%(\mathbf{B})$, and $0.1 \%(\mathbf{C})$ with drop volume of $25 \mu \mathrm{L}$. Abbreviations: FQs, fluoroquinolones; AUC, area under curve. 


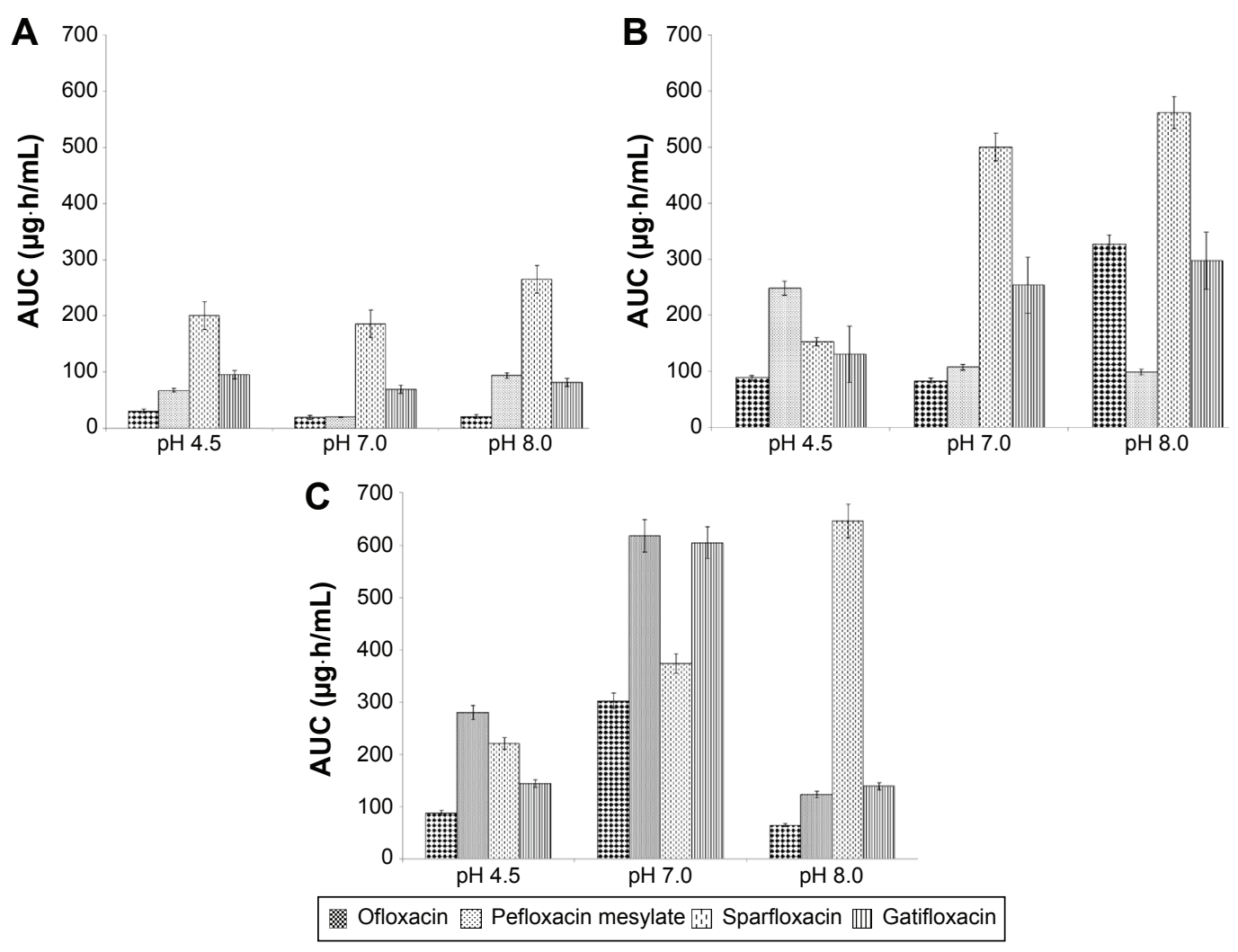

Figure 8 Effect of different $\mathrm{pH}$ on transcorneal penetration of FQs at concentration of $0.025 \%(\mathbf{A}), 0.05 \%$ (B), and $0.1 \%$ (C) with drop volume of $50 \mu \mathrm{L}$. Abbreviations: FQs, fluoroquinolones; AUC, area under curve.

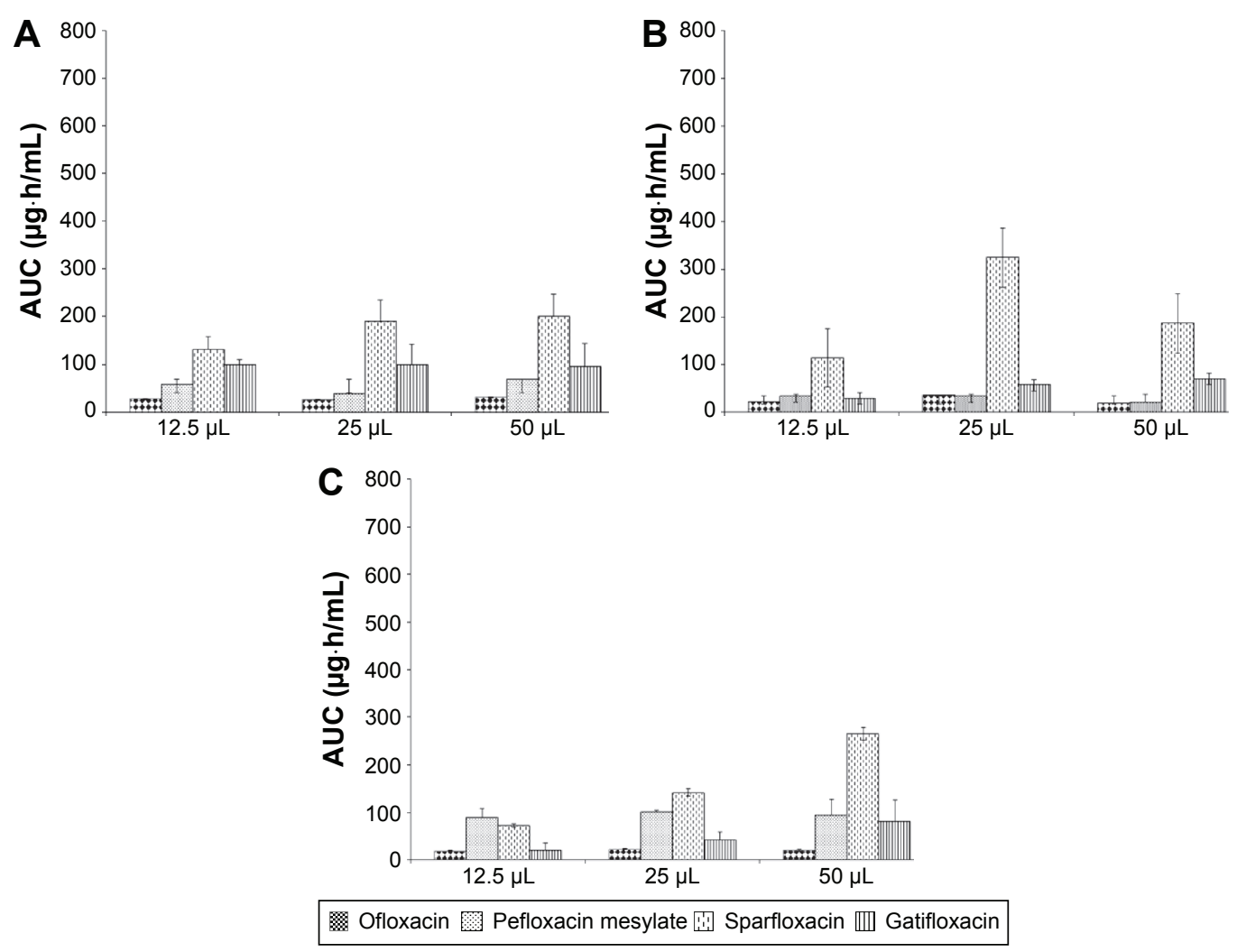

Figure 9 Effect of different volumes of instillation at pH 4.5 (A), pH 7.0 (B), and pH 8.0 (C) on transcorneal penetration of FQs at the concentration of $0.025 \%$. Abbreviations: FQs, fluoroquinolones; AUC, area under curve. 


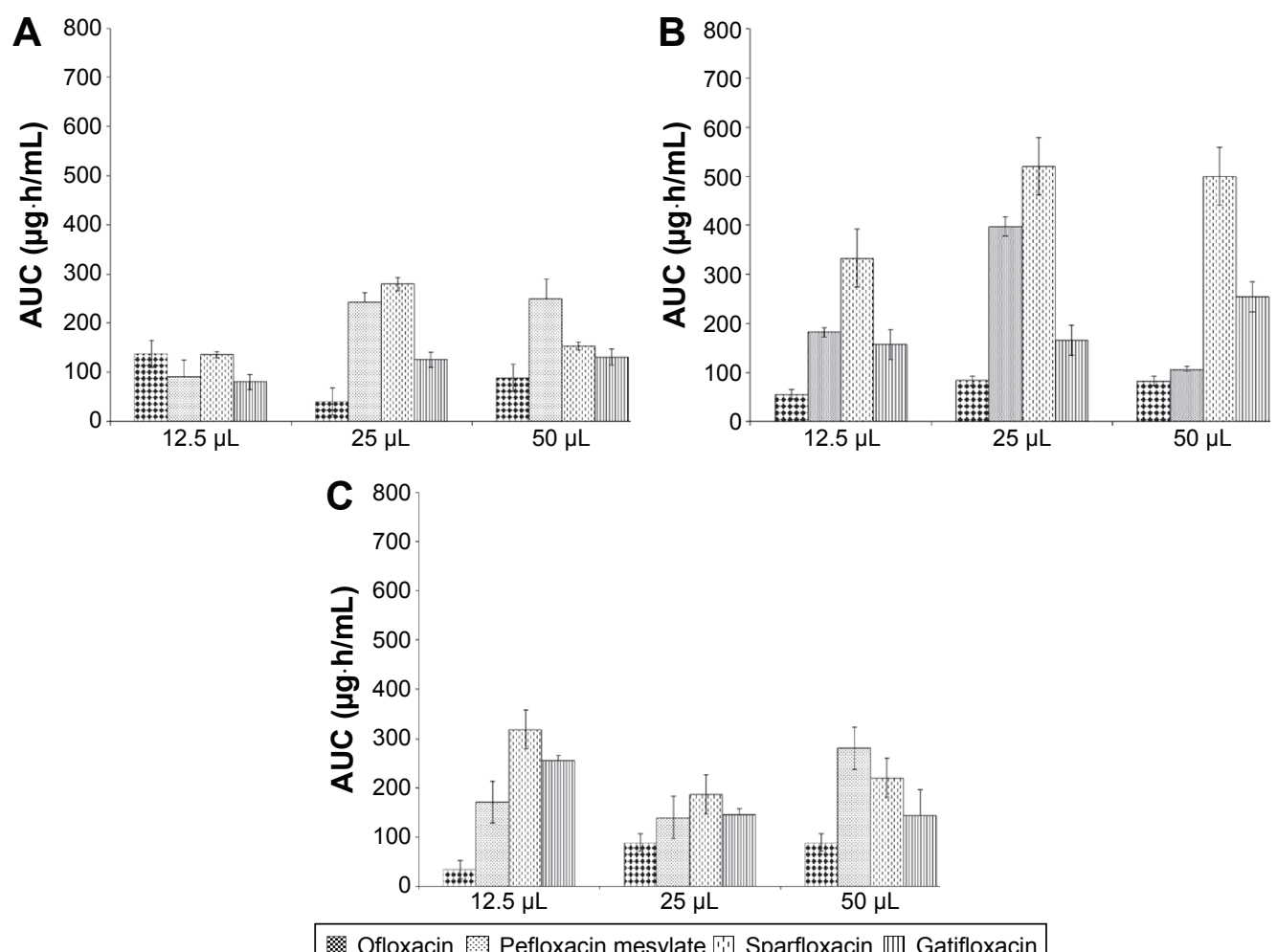

Figure 10 Effect of different volumes of instillation at pH $4.5(\mathbf{A}), \mathrm{pH} 7.0(\mathbf{B})$, and $\mathrm{pH} 8.0(\mathbf{C})$ on transcorneal penetration of $\mathrm{FQs}$ at the concentration of $0.05 \%$. Abbreviations: FQs, fluoroquinolones; AUC, area under curve.

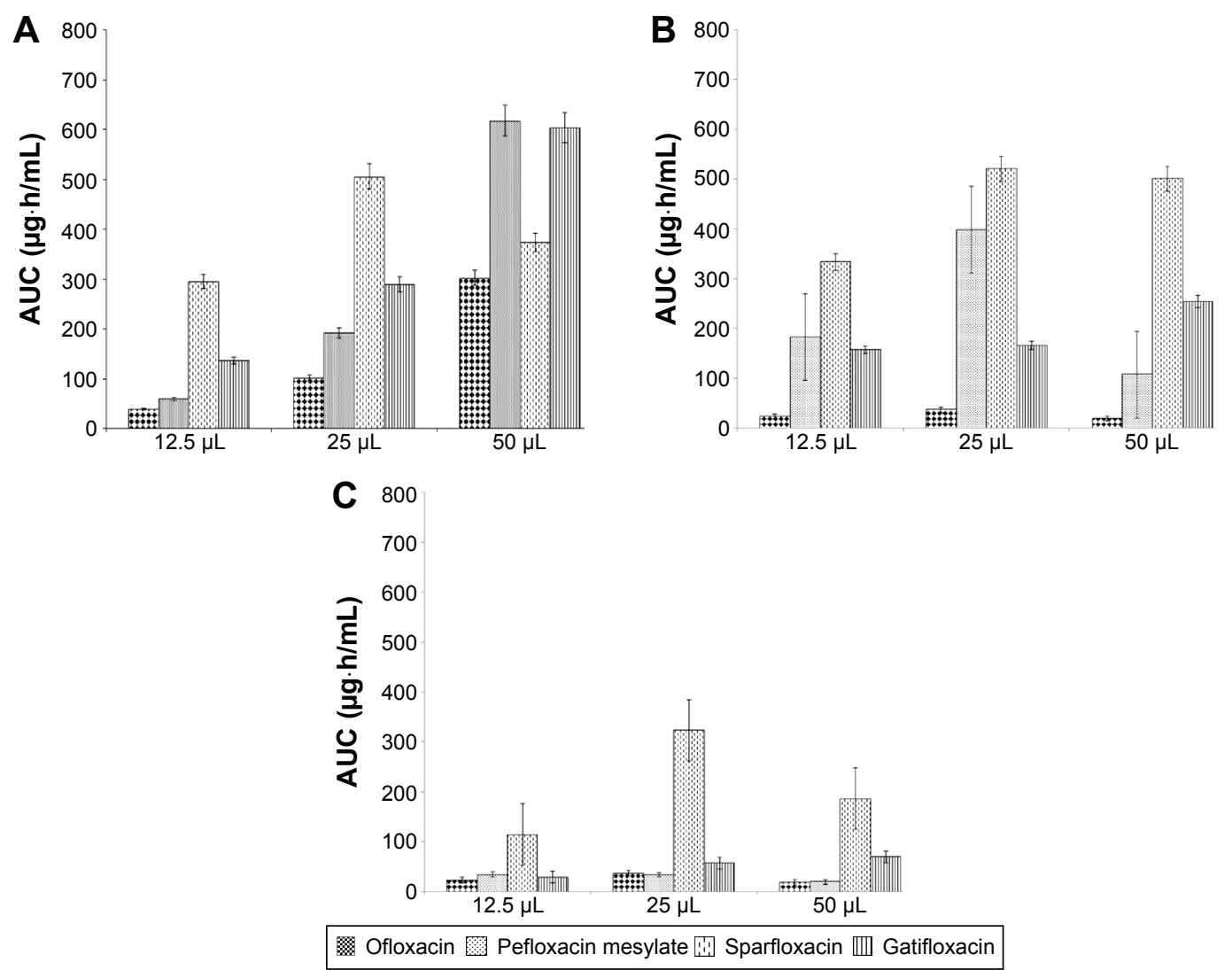

Figure I I Effect of different volumes of instillation at pH 4.5 (A), $\mathrm{pH} 7.0$ (B), and pH 8.0 (C) on transcorneal penetration of $\mathrm{FQs}$ at the concentration of $0.1 \%$. Abbreviations: FQs, fluoroquinolones; AUC, area under curve. 


\section{Discussion}

Cassette dosing (N-in-One) is a high-throughput screening technique, which accelerates the drug discovery process. It has been well exploited to study pharmacokinetics of drugs for various indications leading to lead optimization. This technique allows to investigate more test items while using fewer animals, and hence, reducing the costs. In counterpart, its disadvantages are the potential drug-drug interaction and more challenging analytical procedure. A highly selective and sensitive analytical method is required to detect multiple compounds in a single sample simultaneously. Limited studies report the utility of this technique in ophthalmic drug discovery. A few studies report the in vitro corneal permeability either using cassette dosing technique or individually studying the effect of formulation factors on the transcorneal penetration of FQ (moxifloxacin and gatifloxacin). ${ }^{16,17,19,20}$ However, none of these studies were conducted considering the actual dynamic system which exists in an in vivo setting which depends upon bundle of factors like concentration, lipophilic and hydrophilic properties, degree of dissociation, surface activity, osmotic pressure, and reactivity with corneal tissue.

In our laboratory, we had previously engaged cassette dosing technique to develop a novel in silico model using quantitative structure-property relationship approach with molecular descriptors like $\log P, \mathrm{pKa}$, GAP (difference in $E_{\text {нUмо }}-E_{\text {LUMO }}$, and topological polar surface area along with in vivo corneal permeability. The study was performed at concentration of $0.1 \%$ and volume of instillation as $50 \mu \mathrm{L}$ using HPLC with a few descriptors. ${ }^{18}$ In another study, an ayurvedic polyherbal eye drop (Itone ${ }^{\mathrm{TM}}$ ) was studied for antiangiogenic, anti-inflammatory, anti-cataract, antioxidant, and cytotoxic activity in addition to the evaluation of intraocular penetration in rabbit eyes using LC-MS/MS. ${ }^{21}$ However, in the present study, we comprehensively investigated the effect of formulation factors like concentration, $\mathrm{pH}$, and volume of instillation across the cornea using cassette dosing technique for ophthalmic FQs in an in vivo setting.

Four topically used ophthalmic FQs, viz ofloxacin, sparfloxacin, pefloxacin mesylate, and gatifloxacin, were selected based upon their $\log P$ values and solubility profile to prepare a cocktail formulation. The formulations were prepared at three different concentrations $(0.025 \%, 0.05 \%$, and $0.1 \%)$ and adjusted to three different $\mathrm{pH}$ values $(4.5,7.0$, and 8.0 ), which were instilled at three different volumes $(12.5,25$, and $50 \mu \mathrm{L}$ ) into rabbit's cornea. To avoid any toxic effect of the FQs, maximum dose of the individual FQ was kept as $0.1 \%$ in the cocktail formulation. No mortality or any adverse effect was observed during the entire study. There was significant reduction in total duration for conduct of study and inter-animal variability as same rabbits were used after a washout period of 1 week. In contrast to our earlier study wherein quantification of biosamples was performed using HPLC ${ }^{18}$ in the present study, we used LC-MS/MS as analytical technique to quantify the FQs in aqueous humor. A highly sensitive LC-MS/MS method was developed which was able to elute and quantify four FQs in a single run at different retention times. For statistical analysis, AUC was calculated using linear trapezoidal method to determine transcorneal penetration.

In the present study, boric acid (1.9\%) was used as vehicle for the preparation of cocktail formulations as it has been reported to be an appropriate vehicle for dissolving compounds with basic nature. ${ }^{22}$ Also, boric acid has no interaction with divalent and monovalent cations and thus became a solvent of choice. ${ }^{23}$ Although most of the eye drop formulations contain small amount of benzalkonium chloride $(0.005 \%)$, in the present study, we did not add any preservative. The cocktail formulation was freshly prepared prior to the animal study and was not stored further to avoid any deterioration of FQs or interference with analytical procedure.

In the literature, there are few studies reporting the intraocular penetration of commercially available FQ eye drops after topical instillation into rabbit eyes. They report a good intraocular penetration across cornea, aqueous humor, and anterior vitreous, and they may be considered the penetrative FQs. ${ }^{24-26}$ All these studies were conducted on commercially available formulations and reported the intraocular penetration; however, in the present study, we emphasized the role of different concentrations in transcorneal penetration. We observed that effect of concentration on transcorneal penetration of FQs is dependent on volume of drug instillation up to an extent, and beyond that, there was a decrease in penetration. As we found, increasing all the FQs concentration from $0.025 \%$ to $0.05 \%$ at $\mathrm{pH} 7.0-8.0$ shows a linear increase in transcorneal penetration followed by a fall $(P<0.001)$. Our findings were similar to those of Mitra and Mikkelson ${ }^{27}$ and Maurice, ${ }^{28}$ which report that maximum corneal penetration can be achieved by not only increasing solution concentration but also increasing precorneal contact time at appropriate $\mathrm{pH} / \mathrm{pKa}$ to offer optimal lipid solubility. ${ }^{27,28}$

Lal et al have previously reported that decrease in volume of instillation into the eye increases the fraction of the dose absorbed into the ocular tissue leading to decrease in adverse drug reactions. The findings of that study showed that drop volumes of 10 and $20 \mu \mathrm{L}$ produced more miosis and less side effects than 40 and $80 \mu \mathrm{L}$ in healthy human volunteers. This may be due to more penetration of the drug into the ocular tissue and less drainage into the nasolacrimal system. ${ }^{29}$ 
Another study by Kumar et al also reported the optimal drop volume of $<20 \mu \mathrm{L}$ both from the biopharmaceutical and economic point of view as larger volumes induce risk of adverse systemic effects due to absorption of the drug via the nasal mucosa. ${ }^{30}$ Also, studies report that low-volume method provides a better correlation to human eye irritation experience for some substances. ${ }^{31}$ In the present study, we comprehensively evaluated the effect of volume of instillation along with concentration and $\mathrm{pH}$ in an in vivo setting which has not been reported so far in literature. Our study showed that volume and $\mathrm{pH}$ of formulation are directly related to transcorneal penetration. At all the three studied $\mathrm{pH}(4.5,7.0$, and 8.0) levels, we found that increasing volume of instillation from 12.5 to $25 \mu \mathrm{L}$ decreases transcorneal penetration significantly $(P<0.001)$.

The corneal $\mathrm{pH}$ is reported to have therapeutic and diagnostic significance which attributes in understanding the complexities of disease processes and intolerance of eyes. ${ }^{32}$ As the permeability of weak acids and weak bases is affected by $\mathrm{pH}$, the increase in fraction of un-ionized molecules increases the lipophilicity and ocular absorption. The solubility and stability and corneal permeability of the drugs are quite dependent on $\mathrm{pH}$. If the $\mathrm{pH}$ of formulation is outside the physiological range, eye irritation or ocular discomfort accompanied by an increase in fluid secretion to aid in the restoration of normal physiological conditions exists. Suhonen et al studied effect of $\mathrm{pH}$ on the different pilocarpine delivery as prodrug and as pilocarpine alone. The study showed an increase in corneal permeability when the $\mathrm{pH}$ was decreased from 7.65 to 5.5. The effect of $\mathrm{pH}$ on pilocarpine delivery as prodrug is dependent on prodrug structure, and the advantage gained with prodrugs relative to pilocarpine is dependent on formulation $\mathrm{pH} .{ }^{33} \mathrm{Kompa}$ et al explored the effects of different irrigating solutions on intracameral $\mathrm{pH}$, intraocular pressure, and histological findings after inducing burns using alkali in rabbit eyes. With regard to $\mathrm{pH}$ measurements, their findings suggest that the diluting effect produced by hypo-osmolar irrigants was effective in inhibiting elevated $\mathrm{pH}$ levels. However, to this date, there is no similar animal study, which also explores the effects of eye drops on ocular surface $\mathrm{pH} .{ }^{34}$ In the present study, we found that maximum corneal penetration of all studied FQs was observed at $\mathrm{pH} 7.0$ which is dependent on the concentration (a maximum of $0.05 \%$ followed by $0.025 \%$ ). Also, we observed that increase in $\mathrm{pH}$ to 8.0 at both lower and higher FQ concentrations leads to significant fall in transcorneal penetration. Wei et al studied the effect of $\mathrm{pH}$ on the permeability of timolol in rabbit cornea in vitro.
The study showed that timolol penetrated mainly as a free base by intracellular pathway, and corneal epithelium is a rate-limiting barrier. ${ }^{35}$ In another study, timolol showed an increase (2.5 times) in systemic absorption as $\mathrm{pH}$ of timolol eye drop was increased from 6.2 to 6.9 and $7.5 .{ }^{36}$ The present study also showed highest penetration for all the FQs at the $\mathrm{pH} 7.0$ at concentration of $0.05 \%$ followed by $0.025 \%$ at $\mathrm{pH}$ 4.5. Also, increasing the volume of drug instillation significantly decreased transcorneal penetration at all studied $\mathrm{pH}$. Thus, along with concentration and volume, the $\mathrm{pH}$ of the formulation should be given due consideration and has a paramount importance.

\section{Conclusion}

For the first time, a study reports that factors like drug concentration, $\mathrm{pH}$ of formulation, and volume of drug instillation in vivo in rabbit cornea have a profound effect on transcorneal penetration of FQs. The use of cassette dosing approach to study in vivo pharmacokinetic profile of ophthalmic FQs was quite encouraging.

The study concludes that increase in concentration up to $0.05 \%$ showed a significant effect in the percentage transcorneal penetration. Thereby, the effect of concentration on percentage penetration of FQs is found to be dependent on volume of drug instillation up to an extent, but then, we observed a decrease in transcorneal penetration. Similarly, the $\mathrm{pH}$ of formulation showed that the highest transcorneal penetration of all the FQs was observed at the $\mathrm{pH} 7.0$ at the concentration of $0.05 \%$ followed by $0.025 \%$ at $\mathrm{pH} 4.5$. Lastly, increasing the volume of drug instillation from 12.5 to $50 \mu \mathrm{L}$ showed a significant fall in the transcorneal penetration for most of the FQs. The total effect of increasing the volume of drug instillation at $\mathrm{pH} 7.0$ was a significant decrease in transcorneal penetration for all the studied FQs.

In conclusion, a reduced concentration of drug and volume of instillation with an appropriate $\mathrm{pH}$ need to be considered before designing formulation for ophthalmic usage.

\section{Disclosure}

The authors acknowledge the financial support from Council of Scientific and Industrial Research, Government of India, as senior research fellowship to Charu Sharma, and All India Institute of Medical Sciences for the intramural grant. The authors report no other conflicts of interest in this work.

\section{References}

1. Velpandian T. Intraocular penetration of antimicrobial agents in ophthalmic infections and drug delivery strategies. Expert Opin Drug Deliv. 2009;6(3):255-270. 
2. Sasaki H, Yamamura K, Mukai T, et al. Enhancement of ocular drug penetration. Crit Rev Ther Drug Carrier Syst. 1999;16(1):85-146.

3. Attar M, Shen J, Ling KH, Tang-Liu D. Ophthalmic drug delivery considerations at the cellular level: drug-metabolising enzymes and transporters. Expert Opin Drug Deliv. 2005;2(5):891-908.

4. Nisha S, Deepak K. An insight to ophthalmic drug delivery system. Int J Pharm Stud Res. 2012;3(2):9-13.

5. Baranowski P, Karolewicz B, Gajda M, Pluta J. Ophthalmic drug dosage forms: characterisation and research methods. ScientificWorldJ 2014;2014:861904.

6. Smith A, Pennefather PM, Kaye SB, Hart CA. Fluoroquinolones: place in ocular therapy. Drugs. 2001;61(6):747-761.

7. Appelbaum PC, Hunter PA. The fluoroquinolone antibacterials: past, present and future perspectives. Int J Antimicrob Agents. 2000;16(1): $5-15$.

8. Shaffer JE, Adkison KK, Halm K, Hedeen K, Berman J. Use of "N-inOne" dosing to create an in vivo pharmacokinetics database for use in developing structure-pharmacokinetic relationships. J Pharm Sci. 1999; 88(3):313-318.

9. Allen MC, Shah TS, Day WW. Rapid determination of oral pharmacokinetics and plasma free fraction using cocktail approaches: methods and application. Pharm Res. 1998;15(1):93-97.

10. Frick LW, Adkison KK, Wells-Knecht KJ, Woollard P, Higton DM. Cassette dosing: rapid in vivo assessment of pharmacokinetics. Pharm Sci Tech Today. 1998;(1):12-18.

11. Zhang MY, Kerns E, McConnell O, et al. Brain and plasma exposure profiling in early drug discovery using cassette administration and fast liquid chromatography-tandem mass spectrometry. $J$ Pharm Biomed Anal. 2004;34(2):359-368.

12. Watanabe T, Schulz D, Morisseau C, Hammock BD. High-throughput pharmacokinetic method: cassette dosing in mice associated with minuscule serial bleedings and LC/MS/MS analysis. Anal Chim Acta. 2006; 559(1):37-44.

13. Kadam RS, Kompella UB. Cassette analysis of eight beta-blockers in bovine eye sclera, choroid-RPE, retina, and vitreous by liquid chromatography-tandem mass spectrometry. J Chromatogr B Analyt Technol Biomed Life Sci. 2009;877(3):253-260.

14. Dejneka NS, Wan S, Bond OS, Kornbrust DJ, Reich SJ. Ocular biodistribution of bevasiranib following a single intravitreal injection to rabbit eyes. Mol Vis. 2008;14:997-1005.

15. Ranta VP, Toropainen E, Talvitie A, Auriola S, Urtti A. Simultaneous determination of eight beta-blockers by gradient high-performance liquid chromatography with combined ultraviolet and fluorescence detection in corneal permeability studies in vitro. $J$ Chromatogr $B$ Analyt Technol Biomed Life Sci. 2002;772(1):81-87.

16. Prausnitz MR, Noonan JS. Permeability of cornea, sclera and conjunctiva: a literature analysis for drug delivery to the eye.J Pharm Sci. 1998;87(12):1479-1488

17. Yoshida F, Topliss JG. Unified model for the corneal permeability of related and diverse compounds with respect to their physicochemical properties. J Pharm Sci. 1996;85(8):819-823.

18. Sharma C, Velpandian T, Biswas NR, Nayak N, Vajpayee RB, Ghose S. Development of novel in silico model to predict corneal permeability for congeneric drugs: a QSPR approach. J Biomed Biotechnol. 2011; 2011:483869.
19. Rathore MS, Majumdar DK. Effect of formulation factors on in vitro transcorneal permeation of gatifloxacin from aqueous drops. AAPS PharmSciTech. 2006;7(3):57.

20. Pawar PK, Majumdar DK. Effect of formulation factors on in vitro permeation of moxifloxacin from aqueous drops through excised goat, sheep and buffalo corneas. AAPS PharmSciTech. 2006;7(1):E13.

21. Velpandian T, Gupta P, Ravi AK, Sharma HP, Biswas NR. Evaluation of pharmacological activities and assessment of intraocular penetration of an ayurvedic polyherbal eye drop (Itone $\mathrm{T}^{\mathrm{TM}}$ ) in experimental models. BMC Complement Altern Med. 2013;13:1.

22. Hecht G. Remington-Ophthalmic Preparations. 19th ed. Gebbari AR, editor. Easton, PA: Mack Publishing Company; 1995:1563.

23. Thompson AM. Ocular toxicity of fluoroquinolones. Clin Exp Ophthalmol. 2007;35(6):566-577.

24. Chung JL, Lim EH, Song SW, et al. Comparative intraocular penetration of 4 fluoroquinolones after topical instillation. Cornea. 2013;32(7): 1046-1051.

25. Proksch JW, Ward KW. Ocular pharmacokinetics/pharmacodynamics of besifloxacin, moxifloxacin, and gatifloxacin following topical administration to pigmented rabbits. J Ocul Pharmacol Ther. 2010; 26(5):449-458.

26. Fukuda M, Sasaki H. Calculation of AQCmax: comparison of five ophthalmic fluoroquinolone solutions. Curr Med Res Opin. 2008;24(12): 3479-3486.

27. Mitra AK, Mikkelson TJ. Mechanism of transcorneal permeation of pilocarpine. J Pharm Sci. 1988;77(9):771-775.

28. Maurice DM. Factors influencing the penetration of topically applied drugs. In: Holly FJ, editor. Clinical Pharmacology of the Anterior Segment. Boston, MA: Little Brown and Company; 1980:21.

29. Lal A, Kataria V, Rajpal A, Khanna N. Pharmacodynamic effects of pilocarpine eye drop enhanced by decreasing its volume of instillation. Indian J Physiol Pharmacol. 1995;39(3):267-270.

30. Kumar S, Karki R, Meena M, Prakash T, Rajeswari T, Goli D. Reduction in drop size of ophthalmic topical drop preparations and the impact of treatment. J Adv Pharm Technol Res. 2011;2(3):192-194.

31. Lambert LA, Chambers WA, Green S, et al. The use of low-volume dosing in the eye irritation test. Food Chem Toxicol. 1993;31(2): 99-103.

32. Coles WH, Jaros PA. Dynamics of ocular surface pH. Br J Ophthalmol. 1984;68(8):549-552.

33. Suhonen P, Järvinen T, Koivisto S, Urtti A. Different effects of $\mathrm{pH}$ on the permeation of pilocarpine and pilocarpine prodrugs across the isolated rabbit cornea. Eur J Pharm Sci. 1998;6(3):169-176.

34. Kompa S, Redbrake C, Hilgers C, Wüstemeyer H, Schrage N, Remky A. Effect of different irrigating solutions on aqueous humour $\mathrm{pH}$ changes, intraocular pressure and histological findings after induced alkali burns. Acta Ophthalmol Scand. 2005;83(4):467-470.

35. Wei G, Xu H, Ma Y, Li SM, Zheng JM. Effect of $\mathrm{pH}$ on the permeability of timolol maleate across isolated rabbit cornea. Yао Хие Хие Вао. 2001;36(9):707-710.

36. Kyyrönen K, Urtti A. Effects of epinephrine pretreatment and solution $\mathrm{pH}$ on ocular and systemic absorption of ocularly applied timolol in rabbits. J Pharm Sci. 1990;79(8):688-691.
Drug Design, Development and Therapy

\section{Publish your work in this journal}

Drug Design, Development and Therapy is an international, peerreviewed open-access journal that spans the spectrum of drug design and development through to clinical applications. Clinical outcomes, patient safety, and programs for the development and effective, safe, and sustained use of medicines are a feature of the journal, which

\section{Dovepress}

has also been accepted for indexing on PubMed Central. The manuscript management system is completely online and includes a very quick and fair peer-review system, which is all easy to use. Visit http://www.dovepress.com/testimonials.php to read real quotes from published authors. 